\title{
O EMPREgO DA PLATAFORMA DIGITAL MOODLE COMO ESTRATÉGIA DE E-LEARNING DE SUCESSO
}

\section{ENSAIO TEÓRICO}

GONES, Peter Molina ${ }^{1}$

TANI, Zuleica ${ }^{2}$

GONES, Peter Molina. TANI, Zuleica. O emprego da Plataforma Digital Moodle como estratégia de e-learning de sucesso. Revista Científica Multidisciplinar Núcleo do Conhecimento. Ano 05, Ed. 10, Vol. 14, pp. 135-143. Outubro de 2020. ISSN: 2448-0959, Link de acesso: https://www.nucleodoconhecimento.com.br/educacao/plataforma-digital

\section{RESUMO}

O presente estudo tem por objetivo explorar a temática do e-learning enquanto dispositivo essencial para o ensino e aprendizagem contemporâneos, esmiuçando suas características primordiais, aspectos conceituais, modalidades de ensino, bem como suas vantagens e desvantagens para a sua utilização. Em seguida será abordado mais particularmente a plataforma de ambiente virtual de aprendizagem Moodle, fazendo reflexões a respeito do seu surgimento, sua importância didática, suas funções mais relevantes e aplicabilidade. Serão discutidos aspectos relacionados aos recursos disponíveis, interatividade professor e aluno e construção de conhecimento colaborativo. Ao final, será apresentado um relato da demonstração prática no emprego do Moodle como uma ferramenta que evidenciou benefícios consideráveis junto a alunos de graduação em Enfermagem da Escola Paulista de

\footnotetext{
${ }^{1}$ Mestrando em Tecnologias Emergentes em Educação, Especialista em Enfermagem em Neonatologia, Residência em Enfermagem Clínica, Bacharel em Enfermagem com Habilitação em Enfermagem Médico-Cirúrgica.

2 Orientadora.
} 
Enfermagem da Universidade Federal de São Paulo, na disciplina de Cuidados Intensivos. Concluímos que o Moodle, juntamente com as demais técnicas viabilizadas pelo e-learning, têm um papel preponderante no alcance da educação de alunos e treinamento profissional, se transformando numa orientação bem sucedida para as práticas pedagógicas atuais.

Palavras-chave: E-learning, Moodle, plataformas de ensino, ambiente virtual de aprendizagem.

\section{INTRODUÇÃO}

A capacitação pessoal e profissional se tornou um requisito essencial para um mercado de trabalho cada vez mais exigente e competitivo. $O$ desenvolvimento de competências e o aprimoramento de habilidades atualizadas, além de serem necessários, dizem muito a respeito da qualidade profissional ou do nível de conhecimento exigido. Muitas vezes, conciliar trabalho, aulas e demais atividades vai tornando o dia cada vez menor. As demandas crescentes do dia-a-dia dificultam que seja possível acompanhar os inúmeros papéis que desempenhamos.

O uso de estratégias como o e-learning e o EaD surgiram como um facilitador para muitas dessas questões, seja pelo menor custo, seja quando existem dificuldades no deslocamento, ou ainda quando queremos ampliar a nossa experiência de aprendizagem, tornando-o mais dinâmico e com maiores possibilidades. A evolução da Internet acompanhou todo essa problemática, e há muito tempo também contamos com o smartphone como aliado nesse processo.

O desenvolvimento de diversas plataformas através de vários softwares foi o responsável pela criação dos Ambientes Virtuais de Aprendizagem (AVA), onde acontece toda a aprendizagem, com os seus múltiplos recursos e ferramentas audiovisuais e de exercícios interativos. O foco agora é no aluno, que vai ser o grande responsável pela iniciativa na obtenção do melhor que a plataforma pode oferecer, explorando todas as suas perspectivas. O Moodle, um exemplo de software de aprendizagem, já está na versão 3.9, e é uma dos mais utilizados no mundo, com 
mais de 25000 websites registrados. Sua importância está mais do que consolidada nos dias de hoje.

Neste paper, iniciaremos uma discussão sobre o e-learning, contextualizando aspectos conceituais, pedagógicos, e características principais, sem deixar de citar suas facilidades e limitações. Em seguida, iremos analisar a plataforma Moodle, desde seu surgimento, passando por suas qualidades, ferramentas mais comuns disponibilizadas e sua importância pedagógica. Ao final, faremos um relato de uma experiência de resultado positivo do uso do Moodle em um curso de graduação de enfermagem.

Este será um estudo de natureza bibliográfica, onde o conteúdo será explorado através livros, artigos, websites e periódicos, procurando os conhecimentos mais relevantes disponíveis pelos autores, de forma que seja possível criar um panorama das considerações teóricas e paradigmas relacionados ao enfoque do estudo (LOPES, 2016).

\section{O E-LEARNING COMO FERRAMENTA PEDAGÓGICA}

Atualmente é uma tarefa impossível desassociar as inovações e evoluções no cenário pedagógico, bem como na esfera da educação corporativa, no que concerne à evolução das metodologias de educação à distância, principalmente quando abordamos o e-learning (SILVA, 2006). Com a evolução das tecnologias digitais de informação e comunicação, o campo do e-learning se expandiu cada vez mais, trazendo soluções criativas e originais para o aprendizado eficiente.

Antes de tudo precisamos definir e contextualizar o e-learning. No entender de Lima e Capitão (2003), o e-learning é qualquer experiência de aprendizagem compartilhada pela internet, CD, DVD, e demais conteúdos interativos pelo computador, pois o elearning fundamentalmente não é tecnologia, mas a maneira de ensinar. Ele alterou a forma de encarar a aprendizagem a distância tornando-se o paradigma da aprendizagem dominante. Também poderia ser conceituado como um programa instrucional distribuído online ou pela internet, compreendendo tutoriais enviados no 
campus universitário, workshops, cursos de curta duração e instrução desenvolvida no ambiente de trabalho (RUHE; ZUMBO, 2015).

O e-learning possui algumas características que precisam ser destacadas, dentre as quais o alcance, pois atinge um grande número de pessoas em um curto espaço de tempo; a flexibilidade, oferecendo ao aluno a possibilidade de fazer o curso no melhor local e horário adequados, influenciando em sua relação com o conhecimento; a individualização do treinamento, onde se leva em conta as particularidades de cada aluno em relação à velocidade do aprendizado; o comprometimento e disciplina, pois o e-learning deve buscar motivar o aluno, garantindo sua participação: o foco no aluno, considerando que há uma distância física com o professor, realçando assim as interações do aluno com o curso; a composição do corpo docente, que pode contar com grandes especialistas sem o custo de trazê-los aos locais de aula; e claro, a mídia, com recursos variados desde livros, podcasts, videoconferências, dentre outros (CARDOSO, 2017).

Com base em todas essas caraterísticas, podemos perceber a importância do elearning, levando em consideração a expansão da internet e os serviços por ela disponibilizados, bem como com a adoção do e-learning por instituições tradicionais de ensino, que dedicavam-se somente ao ensino presencial tradicional (MACHADO; GOMES, 2011).

Se a facilidade de acesso e condução do ritmo de aprendizagem são consideradas vantagens importantes do e-learning, podemos acrescentar também que o e-learning se torna uma escolha interessante quando é preciso dispersar informações para alunos que não têm como todos estarem reunidos no mesmo horário, se existirem problemas de mobilidade, incluindo aí idosos e portadores de deficiência, se existe escassez de tempo por parte dos alunos, e se a configuração de uma sala de aula tradicional é mais dispendiosa para a instituição e aluno. Mas não podemos deixar de mencionar algumas desvantagens, como a baixa assimilação por alunos pouco motivados, a falta de um auxílio imediato quando surgirem dúvidas, além da dificuldade de literacia digital de alguns alunos que pode criar barreiras para uma experiência de aprendizagem (ARSHAVSKIY, 2019). 
Em decorrência dos avanços tecnológicos, o e-learning integrou as tecnologias de informação e comunicação (TIC) em vários espaços, sendo os mais comuns aqueles relacionados aos ambientes virtuais de aprendizagem (AVA), que podem ser conceituados como espaços na internet associados à organização de cursos e disciplinas, aplicação de conteúdos de estudo e supervisão dos alunos nas várias modalidades, sejam presencial, semipresencial ou blended learning, ou à distância, no nosso caso, o e-learning. Os AVA são conhecidos como LMS (Learning Management System) ou softwares desenvolvidos com base em algum propósito didático, que empregam uma estrutura tecnológica com qualidades que vão suprir os objetivos pedagógicos dessa modalidade de ensino. Dentre os mais conhecidos e utilizados podemos citar o Blackboard, o GoogleClassroom, o Sakai, o Claroline e o Moodle, que será objeto de nossa discussão no próximo item (BEHAR, 2013).

\section{a) A plataforma Moodle como aliada do ensino}

O ambiente virtual de aprendizagem Moodle (http://moodle.org) é o ponto de partida para vários cursos de e-learning existentes. Pode ser definido como uma plataforma gratuita para o planejamento de cursos a distância ou ainda de interações on-line em sistemas de aprendizagem híbrida, que já foi legitimado por diversas instituições no mundo inteiro (GOHN, 2014). Seu nome é uma sigla para Modular Object-Oriented Dynamic Learning Environment, que traduzindo significa ambiente modular de aprendizagem dinâmica orientada a objetos.

Criado pelo educador e desenvolvedor australiano Martin Dougiamas em 2001, possibilita a criação de comunidades virtuais, destaca o aprendizado colaborativo, é um repositório de recursos educacionais além de ser um software de código aberto (MARCHI, 2013), ou seja, cujo código está disponível para download por qualquer pessoa e a uma filosofia de criação de aplicativos orientada para a colaboração entre os desenvolvedores (KURTZ, 2016). O Moodle tem como principais ferramentas o destaque pela usabilidade, interface intuitiva e especialmente plug-ins, recursos e atividades que são configuradas sem complicação. Sob o ponto de vista pedagógico, o Moodle viabiliza processos de ensino-aprendizagem, através da interatividade, 
valorizando a construção do conhecimento, a autoria, a criação de conhecimento colaborativo bem como a aprendizagem significativa do aluno (SILVA, 2016).

O Moodle oferece formatações específicas para cada curso a ser desenvolvido, que serão desenvolvidas de acordo com o projetista educacional. Juntamente com o docente, ele será o protagonista no processo de elaboração de uma disciplina, sendo encarregado de orientar as escolhas no formato das tarefas e as etapas para que sejam otimizadas e postadas no ambiente virtual (GOHN, 2014).

A plataforma Moodle tem sido constantemente atualizada desde seu lançamento, corrigindo bugs e aprimorando suas qualidades técnicas. Os procedimentos para a instalação e manutenção do Moodle tornaram-se cada vez mais descomplicados, evidenciando que, após a sua customização, a maior parte de responsabilidade caberá aos gestores dos programas educacionais da instituição, sendo que o maior obstáculo passa a ser garantir condições didáticas apropriadas, e não os aspectos técnicos de informática. No site oficial do Moodle, onde o visitante poderá fazer o download da versão mais atual, poderão ser acrescentadas várias ferramentas ao pacote original, promovendo novas funcionalidades, ou melhorias nos aspectos docentes, discentes ou administrativos (SILVA, 2016).

O Moodle, enquanto AVA, foi criado levando em conta que a aprendizagem acontece no decorrer da colaboração do conhecimento, traduzido numa filosofia de saberes compartilhados e desenvolvidos entre o grupo. A possibilidade de prover um feedback, a própria construção do ambiente e do conhecimento dividido, conduz que se adote uma concepção social para o entendimento de sua dinâmica de aprendizagem. Para isso, o software dispõe de várias ferramentas consideradas de informação e comunicação, com destaque para as de interatividade síncrona e assíncrona. As síncronas possibilitam a participação de alunos e professores em datas previamente agendadas, através de chats por exemplo, proporcionando aos envolvidos uma sensação de grupo, importante no incentivo de todos. Já as assíncronas, como por exemplo o Diário, a lição dentre outras, permitem que o usuário organize seus estudos de forma mais organizada e sistemática. As ferramentas mais comuns no Moodle são as seguintes; arquivo de Materiais, Lição, Fórum, Tarefa, Questionário, Glossário, 
Pesquisa de Opinião, wiki, Pesquisa de avaliação, Diário e Diálogo (SOUSA; MOITA; CARVALHO; 2011).

Além de todas as vantagens do Moodle como plataforma de e-learning, já elencadas anteriormente, cabe ressaltar que o software dispõe de uma equipe de suporte, oferece qualidade nos serviços e é um referencial no mercado. Ele amplia a circulação do conhecimento, promove interatividade, é de fácil manuseio, transforma o professor num intermediário no processo de aprendizagem e não mais o elemento central, pode ser utilizado em diferentes cursos e modalidades, e conta com um sistema avaliativo eficiente. No aspecto mais restritivo, podemos destacar a dificuldade de acesso a alguns links, a limitação no desenvolvimento de recursos gráfico-visuais, a falta de um sistema de busca, a necessidade de familiarização com tecnologia, e a necessidade de dedicação docente na preparação do ambiente de ensino (SILVA, 2013; VIALI, 2020).

b) O sucesso do Moodle na prática

Durante esta pesquisa, encontrei inúmeros relatos de experiência com o uso da plataforma Moodle, demonstrando a excelente aplicabilidade em diversos cursos e situações de aprendizagem. Como profissional da saúde, busquei encontrar algum indicador relacionado à assistência de enfermagem, mais especificamente na área de terapia intensiva. Sabemos o quanto é difícil o cuidado prestado ao paciente crítico, e uma forma de facilitar e otimizar a assistência, principalmente na área de graduação, revela-se um fator significativo.

No caso, a utilização da plataforma foi entre estudantes de enfermagem de graduação da Escola Paulista de Enfermagem da Universidade Federal de São Paulo (UNIFESP). O estudo dividiu os alunos em Grupo Controle e Experimento, este último que fez uso da plataforma Moodle, englobando vários conteúdos relacionados ao cuidado ao paciente grave. Foram utilizados os fóruns de discussão além de compartilhamento de dúvidas e opiniões. No Grupo Controle, o mesmo conteúdo era oferecido, porém sem o uso do AVA (DOMENICO; COHRS, 2016). 
Após uma criteriosa avaliação dos estudantes, inicialmente com o emprego de exames escritos, e posteriormente englobando também a técnica de Grupo Focal para avaliar a percepção dos estudantes sobre a aprendizagem dos conteúdos oferecidos, foi constatado que a utilização do Moodle facilitou o processo de ensinoaprendizagem, com o elevado desempenho dos alunos do Grupo Experimento. Para estes alunos, a execução das atividades oferecidas pelo Moodle, possibilitou-Ihes a conquista de conhecimentos e habilidades que ajudaram na compreensão da prática, criando condições favoráveis para o desenvolvimento de maior autoconfiança na assistência prestada ao paciente grave internado numa unidade de terapia intensiva (DOMENICO; COHRS, 2016).

Isso vai refletir diretamente em dois importantes aspectos: a melhoria na formação do aluno, que mais bem preparado estará mais apto ao mercado de trabalho; e também no aperfeiçoamento do cuidado oferecido a esse tipo de paciente em particular, extremamente dependente das ações de enfermagem e do cuidado especializado, que é vital para a manutenção e recuperação do seu quadro crítico.

\section{CONSIDERAÇÕES FINAIS}

Ao final da discussão e análise a respeito do e-learning e do Moodle enquanto estratégias robustas para um aprendizado eficiente e atual, foi possível percebermos o tamanho da evolução estabelecida na área de ensino, na qual a Internet desempenhou um papel decisivo. Hoje é possível a cada vez um número maior de pessoas, o acesso a cursos em faculdades, pós graduação e atualização constante através da tecnologia desenvolvida em ambientes virtuais. Com um ponto de conexão à Internet e um dispositivo de visualização, podemos alcançar o conhecimento mais distante, interagirmos com diferentes culturas e aprimorarmos cada vez mais nossos conhecimentos.

Podemos ressaltar também, que ocorre um progresso real no uso da plataforma Moodle na aquisição e assimilação de temáticas de ensino-aprendizagem, aumentando a contribuição que esses softwares trazem para a educação. Nos dias críticos que vivemos, de distanciamento provocado pela pandemia do Covid-19, a 
adaptação às atividades online se tornou praticamente obrigatória, reclamando urgência de professores e alunos na busca de atualização para que o tempo não seja perdido. O ensino híbrido se desenvolveu em proporções gigantescas, e parece se revelar numa orientação da educação. $O$ desenvolvimento de competências relacionadas ao mundo digital é atualmente questão de sobrevivência, onde até o trabalho remoto já mostra sinais que irá persistir.

Futuramente, esperamos que um número ainda mais expressivo de estudantes e professores tenham acesso às plataformas de ensino online e que a divulgação de cursos e informações imprescindíveis sejam feitas de modo frequente e regular, afim de que a formação e o preparo possam se estender universalmente.

\section{REFERÊNCIAS}

ARSHAVSKIY, Marina. Design Instrucional para ELearning: guia essencial para criar cursos de e-learning bem sucedidos. Nova lorque (e book): Babelclube Inc.Estados Unidos, 2019.

BEHAR, Patrícia Alejandra. Competências em educação a distância. Porto Alegre: Penso Editora, 2013.

CARDOSO, Fernando. Gestores de e-learning. São Paulo: Saraiva, 2017.

DOMENICO, Edvane Birelo Lopes De; COHRS, Cibelli Rizzo. Plataforma Moodle na construção do conhecimento em Terapia Intensiva: estudo experimental. Acta Paulista de Enfermagem, v.29, n.4, p.381-389, 2016.

GOHN, Daniel Marcondes. Educação musical a distância: abordagens e experiências. São Paulo: Cortez, 2014.

KURTZ, João. O que é software de código aberto? TechTudo, 2016. Available: https://www.techtudo.com.br/dicas-e-tutoriais/noticia/2016/03/o-que-e-software-decodigo-aberto.html, [Accessed 19 July 2020]. 
LIMA, Jorge Reis; CAPITÃO, Zélia. E-learning e E-conteudos. Portugal: Edições Centro Atlantico Portugal, 2003.

LOPES, Jorge. O fazer do trabalho científico em ciências sociais aplicadas. Pernambuco: Editora Universitária UFPE, 2016.

MACHADO, Claudia; GOMES, Maria João. Adoção de práticas de e/b-learning no ensino superior: um estudo de caso. IE Comunicaciones. Revista Iberoamericana de Informática Educativa, v.14, n.2, p.25-35, 2011.

MARCHI, Miriam. Moodle básico: Apostila. São Paulo: Heuristicons, 2013.

RUHE, Valerie; ZUMBO, Bruno D. Avaliação de Educação a Distância e E-learning. Porto Alegre: Penso Editora, 2015.

SILVA, Marco. Avaliação da aprendizagem em educação online: fundamentos, interfaces e dispositivos, relato de experiências. São Paulo: Loyola, 2006.

SILVA, Robson Santos. Ead como produzir e comercializar cursos online (EBOOK). Santa Catarina: Clube de Autores, 2013.

Moodle 3 para gestores, autores e tutores: Educação na Era Digital. São Paulo: Novatec, 2016.

SOUSA, Robson Pequeno; MOITA, Filomena M.C; CARVALHO, Ana Beatriz Gomes. Tecnologias digitais na educação. Campina Grande: EDUEPB, 2011.

VIALI, Lorí. Better together: o uso de tecnologias digitais na educação do Brasil e da Espanha. Rio Grande do Sul: EdiPUCRS, 2020.

Enviado: Setembro, 2020.

Aprovado: Outubro, 2020. 